\title{
Reconciling Epicurean Friendship and Egoism Through a Rule Egoist Reading
}

\author{
Aashka Gupta ${ }^{1}$ \\ ${ }^{1}$ McDowell High School, Erie, Pennsylvania, USA
}

\section{ABSTRACT}

Ancient Greece gave rise to many prominent philosophical figures. Of these, a notable academic was Epicurus (341 270 BC), a Samoan who was influential in the development of the Stoic school of thought. While Epicurus's scholarship includes several subject areas, he is most notable for his work in ethics and egoism. As a subset of this philosophical field, Epicurus investigates the role of a selfless, virtuous friendship in the cultivation of a moral life, as well as the need for a selfish and rational egoism. Thus, as scholars have pointed out, the notions of selfless friendship and self-interest egoism, while maintained parallelly by Epicurus, seem to be in tension with each other. This paper examines the relationship between an ideal Epicurean friendship and Epicurus's concept of egoism, and attempts to resolve both notions under a reading of rule egoism.

\section{Introduction}

The concept of friendship was important to Epicurus; few philosophers had developed the view of philia $^{1}$ prior to Epicurus. Maintaining an Epicurean friendship requires the needs of a friend to be valued no differently than the needs of his or her own. Not only must a friendship be choiceworthy for itself, but, if necessary, sacrifices must also be made for a friend. ${ }^{2}$ Diogenes Laertius, ${ }^{3}$ Lives of Philosophers 10.12 even holds, "He on occasion will die for his friend." However, equally important to Epicurus was his paradigm of egoism; Epicurus was a staunch egoist and held that the only goal intrinsically valuable to oneself was obtaining pleasure. All other seemingly valuable notions were just a means to obtain a certain amount of self-interested pleasure consistent with egoism.

Parallelly maintaining the philosophies of egoism and virtuous friendship seems problematic. For Epicureans, reconciling the notion of a selfless and virtuous friendship with the equally important notion of egoism seems problematic. In this paper, I aim to show that it is possible for virtuous friendship and egoism to co-exist when friendship is seen as a general, self-interested rule for acquiring pleasure. I utilize a theory similar to ethical egoism, termed rule egoism, to explain how such a conclusion can be drawn. Thus, I ask the question: Under the egoist theory of rule egoism, how can Epicurean friendship be reconciled with a paradigm of Epicurean egoism?

This paper consists of five sections. First, I provide necessary background on the relevant philosophies of Epicurus (in the order of ethical egoism, rule egoism, and friendship). In the second section, I review the literature surrounding the paradox of Epicureanism and friendship. In the third section, I present evidence of rule egoism present in Epicurean

\footnotetext{
${ }^{1}$ From the Ancient Greek translation of the term 'friendship'. The context of philia refers to a platonic friendship based in camaraderie.

${ }^{2}$ Margheim (2013) p. 2

${ }^{3}$ Ancient Greek biographer, known for his compilation of the works of Greek philosophers, sophists and orators. Laertius' anthology of Epicurean texts remains a keystone in the field.
} 
text. Next, I introduce problematic interpretations of friendship and examine them under the pretense of rule egoism. Lastly, I explain how the notion of friendship can be reconciled with Epicureanism under the paradigm of rule egoism.

\section{Ethical Egoism}

Previous Epicurean scholars have interpreted Epicurus to remain committed to maintaining ethical egoism. ${ }^{4}$ Ethical egoist theories are not unique to Epicurus, however; ethical egoism has received philosophical prominence and has been featured in the works of multiple philosophers. While there are variations of ethical egoism depending on its use, Epicurus's version of ethical egoism maintains that "human conduct should be based exclusively on self-interest." Thus, under a theory of ethical egoism, everyone ought to do only what can be reconciled with their individual selfinterests. Every individual action performed by an ethical egoist must be productive toward some pleasure or rational self-interest.

\section{Rule Egoism}

Although ethical egoism has been explored and refined by contemporary philosophy, a theory similar to ethical egoism, rule egoism, has lacked scholarly attention. The most significant contribution towards establishing a formal definition for rule egoism comes from John Hospers: "rule-egoism is the principle that one should observe those rules whose adoption would be to one's interests." ${ }^{, 6}$ Accordingly, there is one major distinction between rule egoism and ethical egoism:

\section{Rule versus Action}

Ethical egoism maintains that, as a rational actor, one should perform the individual acts which are productive toward self-interest. Therefore, an ethical egoist analyzes individual actions and their consequences. Conversely, rule egoism is concerned with the implementation of general principles. ${ }^{7}$ A rule egoist evaluates the premise of positions and decides whether the universal implementation of that premise would be beneficial towards their own self interest. In other words, a rule egoist does not evaluate the consequences of individual actions like the ethical egoist does. He instead evaluates the consequences of the adoption of the general rule in question.

Consider, for example, a hungry street-traveler that comes upon a cart of bananas. If our traveler were an ethical egoist, she might decide that stealing a banana off the cart would be a rational action since it would be productive toward her interest of fulfilling her hunger. Assuming the thief has a rational chance of not being caught and reprimanded, stealing the banana would be consistent with a paradigm of ethical egoism.

However, if our hungry traveler were a rule egoist, she would not weigh the consequences of stealing a banana in this case only. She would, instead, weigh the consequences of adopting the general rule of stealing while hungry. In other words, she might ask herself "will it always be productive for me to steal to satisfy my hunger?" In this case, our rule egoist may find that even though she may not be punished this time, there would eventually come a time when her stealing would lead to consequences that are not productive toward her self-interest (jail time). ${ }^{8}$ Therefore, a rule egoist would likely avoid the action of stealing.

Rule egoism, then, is concerned with evaluating the consequences of an action if it were performed in every instance, in contrast with ethical egoism which examines the individual consequences of performing an action.

\footnotetext{
${ }^{4}$ O'Keefe (2001) p. 1

${ }^{5}$ Regis (1980) p. 51

${ }^{6}$ Hospers (1973), p. 393

${ }^{7}$ Baird (2011) p. 32

${ }^{8}$ Hospers (1973), p. 393
} 


\section{Epicurean Friendship}

Epicurus has high regard for the value of friendship; he describes the ideal virtuous friendship as one which provides mutual benefits to both friends. Not only did Epicurus promote the material benefits of friendship, but he also stressed the psychological benefits of knowing such help was available. Consider VC 34 which states, "we do not need utility from our friends so much as we need confidence concerning that utility." Epicurus maintains that while the help of a friend may not be a constant necessity, the benefit gained from knowing that help is available is a constant pleasure. Such a society of friendship is critical in both psychological and physical safety- friends are needed to both "protect one another from danger and provide for one another in time of need." 9

\section{Literature Review}

The literature on Epicurus's relationship with egoism generally diverges into two camps of thoughts. Compatibilists hold that the theory of Epicurean friendship can be reconciled with Epicurus's egoistic paradigm. Incompatibilists, on the other hand, hold that Epicurean friendship and Epicurean egoism remain incompatible. Hallmarks of the incompatibilist camp include noted Epicurean scholars such as Julia Annas and Philip Mitis, who argue that virtuous friendship seems to conflict with Epicurus's egoism. ${ }^{10} 11$ They rely primarily on the argument that "If $\mathrm{X}$ is a genuine friend of Y, then X values Y's well-being for ... Y's own sake." ${ }^{12}$ Since such a position seems to contradict the self-regarding nature of egoism, in which actions are taken for solely rational self-pleasure. Therefore, Annas and Mitis dismiss the compatibility of friendship.

On the contrary, competing paradigms have been developed in the compatibility camp. Scholars Evan Brown and Matthew Evans both offer the compatibilist perspective that there exist interpretations of Epicurean friendship that succeed in upholding Epicurean egoism. ${ }^{13} 14$ As Brown maintains, every action that works toward (a truly virtuous) friendship is an action that produces happiness or is productive toward self interest. ${ }^{15}$ Thus, Brown argues that even though friendship requires initial sacrifices, the concept of a virtuous friendship is beneficial as a whole. Implementing the previous argument as a general foundation, compatibilists contend that Epicurean friendship can be maintained with Epicurean egoism.

The dichotomy between the literature surrounding Epicurean friendship leaves an unresolved gap in the literature that has been previously unrecognized by Epicurean scholars. Camps of compatibility are focused on the reconciliation of altruistic friendship with ethical egoism. However, few have considered the compatibility between friendship and other forms of egoism, like rule egoism. In fact, most of the literature surrounding Epicureanism brands Epicurus as a staunch ethical egoist. ${ }^{16}$

There are notable exceptions to the interpretations of egoism and friendship William Baird's reconstruction of friendship is unique in that it operates in the space between both camps of compatibility. ${ }^{17}$ Baird argues that the tension between Epicureanism and friendship can be relieved by viewing friendship as functioning as an end to meet a larger goal consistent with individual self-interest. In this way, he seems to operate in the ground between both camps of compatibility. I take the work of Baird one step further and examine Epicureanism through a different ethical

\footnotetext{
${ }^{9}$ O'Keefe (2001), p. 9

${ }^{10}$ Annas (1987)

${ }^{11}$ Mitis (1988)

${ }^{12}$ Margheim (2013) p. 5.

${ }^{13}$ Brown (2002)

${ }^{14}$ Evans (2004)

${ }^{15}$ Brown (2002) p. 73

${ }^{16}$ Hospers (1973) p. 393

${ }^{17}$ Baird (2011) p. 1
} 
theory. I follow an approach similar to Baird, but I interpret Epicurus's work through rule egoism rather than ethical egoism. ${ }^{18}$ I then attempt to reconcile the notion of compatibility and virtuous friendship by interpreting friendship through rule-egoism and justifying its existence as a means of rational self-interest.

\section{Methodology}

This methodology has two components. First, I present criteria for selecting primary-source texts. Next, I describe how, through a method of content analysis, the selected texts were interpreted under the ethical theory of rule egoism.

\section{Criteria for Source Selection}

Epicurus's school of thought is voluminous; he developed positions on divinity, physics, ethics, and epistemology. As was standard among ancient Greek philosophy, much of the written records of Epicureanism were produced on papyrus and intended to be read as lecture notes. Many primary texts (written by Epicurus himself and his followers) have fallen foe to natural disasters and wear due to time. Therefore, contemporary reproductions of Epicurean philosophy reflect only a small subset of Epicurus's actual teachings which presents several translatory challenges. Firstly, existing primary documentation of Epicureanism is often in the form of letters from Epicurus to his acquaintances or close friends' reproductions of Epicurus's philosophy. It is important, then, to differentiate others' misrepresentations (intentional and unintentional) from what Epicurus had intended us to understand. Secondly, documents that have been confirmed to have been authored by Epicurus are presented as a collection of tenets central to Epicureanism. ${ }^{19}$ These documents tend to be wide-ranging and unsorted in scope-whole documents are often not relevant to a thematic approach to Epicureanism. Scholars, then, must take precautions in selecting only those sections of text that pertain to the niche of philosophy examined. Finally, much of the text that remains is penned in Greek; English-based interpretations risk losing significance attributed to the vernacular of specific Greek words and phrases. There has been much scholarly debate on the nature of the interpretation of many Epicurean texts. Because the focus of this paper entails an investigation of Epicurean primary sources, it is necessary to include the criteria for source selection in an attempt to avoid the problems discussed above. Accordingly, two benchmarks were examined. The dual approach of the first part of this methodology is based on the work of Augustin Riska, ${ }^{20}$ one of the first philosophers to introduce a formal methodology in philosophical research. The two categories discussed mirror the ones Riska established.

\section{Relevance of Primary Texts}

A keystone compilation of Epicurus's philosophy is provided by Diogenes Laertius, an ancient Greek biographer and philosopher. Although Laertius remains an important source of record of Epicurus's school of thought, literary challenge arises when interpreting Laertius's compilations of Epicurean philosophy due to the voluminous nature of work recorded. For example, Laertius outlines in Lives of Eminent Philosophers key tenets of Epicureanism (from the atomic swerve to the merits of religion). Therefore, careful consideration was kept in narrowing the field of inquiry to specifically Epicurean texts that concerned three subject matters (as a filter between necessary and unnecessary texts).

\footnotetext{
${ }^{18}$ It is important to note two distinctions in the methodology used that makes it novel from the ones currently utilized in philosophy: First, it considers a newly-developed ethical theory (rule egoism) in reconciling Epicureanism and Epicurean friendship. Second, it utilizes a system of content analysis and source selection (rather than arbitrary inclusion of texts) to justify interpretations of Epicurus under the paradigm of rule egoism. See Methodology section for a detailed account of the methodology utilized.

${ }^{19}$ For example, Sententiae Vaticanae (Vatican Sayings) is presented as a series of 81 statements rather than a collection of treatises differentiated by subject.

${ }^{20}$ Riska (1972)
} 
All included texts concerned either Epicurus's view on self-interest or egoism as related to friendship or as requirements for maintaining an Epicurean friendship.

\section{Authentication of Selected Texts}

After relevant primary sources were selected and categorized into one of the three aforementioned subject matters, investigation of the origin of the text was completed. As previously mentioned, Epicurus's literary legacy was in large part due to the notes of his pupils or followers. Epicurus also wrote extensively to select friends and relations, making the majority of the Epicurean literary base either informal or authored by someone other than Epicurus himself. For example, key Epicurean texts like Writings of Cicero (a comprehensive history of Greek philosophers and orators written by Marcus Tullius Cicero) are a topic of controversy of the Epicurean academia. Cicero himself lived and authored Writings of Cicero nearly half a century after Epicurus founded his school of thought. Scholars, therefore, call into question the reliability of texts that possess a time gap between publication of the text and the teachings of Epicurus. Thus, all selected texts were verified to include a time span of no more than twenty years from the tentative publication date to the death of Epicurus. Such a time frame not only allows for a more accurate representation of Epicurus's actual teachings (rather than reproductions of them), and is also applied in Riska's methodology in philosophy. ${ }^{21}$

The criteria of source selection were applied to seventeen remaining documents of Epicureanism. ${ }^{22}$ Based on the established criteria, three first-hand sources were included to be analyzed through a content analysis methodology- Epicurus's Letter to Menoceus: Diogenes Laertius 10.121-135, Letter to Lucretius 6.1-28, and The Vatican Collection of Epicurean Sayings.

\section{Content Analysis}

To evaluate the sources chosen in accordance with the first part of the methodology, a qualitative content analysis method was utilized. Qualitative content analysis is a field of document inquiry that focuses on the subjugated intentions behind an author's work. ${ }^{23}$ Specifically, content analysis is "the selection and rational organization of categories that condense the substantive meanings of the given text, with a view to testing pertinent assumptions."24

\section{Justification}

Philosophical research is grounded in the premise of both subjective interpretation and logical analysis of texts. Therefore, a suitable methodology in philosophical research must make it "possible ... to consider philosophy as a subject matter of investigation." ${ }^{25}$ A qualitative content analysis methodology remains consistent with this requirement. Qualitative content analysis is founded on the principle of condensing portions of text into key tenets. ${ }^{26}$ Due to their nature, content analysis methodologies do not require analysis of voluminous amounts of literature. Therefore, focus can be placed on a few documents central to the research being conducted without compromising the accuracy that is generally maintained when analyzing a larger pool of literature. This is an especially important benefit in the field of philosophy; the majority of philosophical research conducted does not concern itself with analyzing large volumes of data. Instead, philosophical procedures often narrow the scope of inquiry to a few selected texts, and subjective

\footnotetext{
${ }^{21}$ Riska (1972)

${ }^{22}$ These seventeen sources were included in a compilation of Epicurus teachings by Long \& Sedley and Inwood \& Gerson.

${ }^{23}$ Bardach-Yalov (1972), p. 26

${ }^{24}$ Kracauer (1952-1953, pp. 637-638)

${ }^{25}$ Riska (1972)

${ }^{26}$ Bardach-Yalov (1972), p.27
} 
analysis is performed. ${ }^{27}$ Therefore, qualitative content analysis as a general methodology remains highly appropriate for disciplines concerned with subjective interpretation (exp. philosophy). ${ }^{28}$

In accordance with standard qualitative content analysis methodologies, included documents were coded and analyzed. The content utilized is influenced by both Bardach-Yalov's qualitative content analysis in analyzing influences to propaganda, and Riska's attempt to introduce a formal qualitative methodology in philosophy.

\section{Document Coding}

As per the source selection methodology, three sources were included and coded for purposes of this paper. Sources that were included were accessible through the translations of philosophical sources by Long \& Sedley and Inwood $\&$ Gerson. ${ }^{29}{ }^{30}$ Coding was conducted per the Bardach-Yalov approach. ${ }^{31}$ This approach relies on the grouping of data into previously identified clusters or themes. These clusters are then analyzed alongside each other to identify common themes running through multiple texts. Since the goal of document coding was to identify sources concerned with Epicurean friendship and egoism, sources were coded on three categories: (1) Epicurean friendship/philia, (2) Epicurean egoism, (3) Epicurean pleasure/eudaimonia. ${ }^{32}$ In order to determine whether one of the three categories were present, each section corresponded with indicator words that signaled the presence of one (or more) of the three categories. Data table 2 includes a complete list of indicator words for each of the three categories. Once an indicator word was present, the section of the text that was relevant to the word was coded as a section of text consistent with one of the three categories mentioned. Data Table 1 provides an excerpt of text from Letter to Lucretius which includes an indicator word and the text that was coded based on the presence of the word.

Table 1: Excerpt from Letter to Lucretius 6.1-28

Every pleasure qua pleasure is good, and every pain qua pain is bad $\left(\mathrm{A}_{5}, \mathrm{~B}_{3}, \mathrm{D}_{1}\right)$. But the 'natural affinity of every pleasure and the converse for every pain are not reasons for pursuing the former and avoiding the latter irrespective of circumstance $\left(\mathrm{A}_{5}, \mathrm{~B}_{3}\right)$. I.e. not every pleasure is choiceworthy. The groups of this proposition introduce us to the most distinctive feature of Epicurus' hedonism: 'the greatest pleasure is the removal of all pain' $\left(\mathrm{A}_{6.8}, \mathrm{cf} . \mathrm{B}_{1-2} \mathrm{C}_{1}, \mathrm{E}_{\mathrm{l}}\right)$. If complete absence of bodily and mental pain constitutes the greatest pleasure, then it is only reasonable to avoid any pleasures which will imperil this objective, or to accept any pains which will help secure it. Epicurus develops his hedonistic calculus accordingly $\left(B_{3}, c f . D_{13,} H_{3}\right.$, and recommends the avoidance of all pleasure sources which are likely to result in an excess of pain. At first glance the denial of 'anything in between pleasure and pain' $\left(\mathrm{A}_{7}\right)$ seems counterintuitive. Plato had made this point (Republic 9,583c-584a) arguing that it is just an illusion when in pain to think that the ending of the pain will actually be pleasure. However, his argument depends upon the assumption that both pleasure and pain are movements, with the absence of either constituting a state of rest.

\footnotetext{
${ }^{27}$ Riska (1972)
}

${ }^{28}$ Bardach-Yalov (1972), p. 26

${ }^{29}$ Long and Sedley (1987)

${ }^{30}$ Inwood and Gerson (1988)

${ }^{31}$ Bardach-Yalov (1972)

${ }^{32}$ Eudaimonia was an ancient Greek term loosely translated as 'happiness' or 'complete pleasure'. Epicurus used the term generously when describing his egoism, and modern translation of his text leave eudaimonia in its Greek form rather than translating it to its English counterpart. Therefore, it was included as a category since it was helpful in describing Epicurean egoism. 
Table 2: List of Indicator words by category

\begin{tabular}{|l|l|}
\hline & Indicator Words \\
\hline $\begin{array}{l}\text { Category 1: Epicurean Friend- } \\
\text { ship/philia }\end{array}$ & Friend, friendship, virtuous friendship, philia, neighbor, society of friends \\
\hline Category 2: Epicurean egoism & Egoism, ethical egoism, egoistic paradigm \\
\hline $\begin{array}{l}\text { Category 3: Epicurean pleasure/eu- } \\
\text { daimonia }\end{array}$ & $\begin{array}{l}\text { Pleasure, pain, hedonism, hedonistic desire, static pleasure, complete } \\
\text { pleasure, eudaimonia }\end{array}$ \\
\hline
\end{tabular}

\section{Analysis of Coded Data}

Once all relevant texts were coded, common themes among different sources were identified. There were three main goals during the process of data analysis: 1) to provide literary evidence that Epicurus's philosophy can be interpreted as a rule-egoistic philosophy. 2) to show that rule egoism (as a general principle) is compatible with Epicurean friendship, and 3) to show that Epicureanism (when interpreted under rule egoism) is compatible with Epicurean friendship. When reworded slightly, it becomes apparent that the third goal is an answer on the ultimate question this paper aims to answer: is Epicureanism compatible with Epicurean friendship through rule egoism? Therefore, if all three goals were achieved during the process of data analysis, Epicurus's friendship was reconciled with his egoism (a compatibilist view). However, if one of the three identified goals remained unfulfilled, then it was taken that Epicurean friendship and egoism were incompatible.

\section{Analyzed Data}

The sources Letter to Lucretius 6.1-28, ${ }^{33}$ Epicurus's Letter to Menoeceus: Diogenes Laertius 10.121-135, ${ }^{34}$ and The Vatican Collection of Epicuren Sayings ${ }^{35}$ were all analyzed in accordance with the methodology. After the coding process was completed, each of the three sources was aligned to one of the aforementioned goals. This was done by identifying the indicator words present in individual sources, and aligning those indicator words to one of the three aforementioned goals. For example, Letter to Lucretius ${ }^{36}$ and Diogenes Laertius offered a multitude of indicator words that dealt mainly with Epicurus's views on pleasure. Therefore, Letter to Lucretius and Diogenes Laertius were both analyzed to meet goal (1) which also dealt with Epicurus's views on pleasure. Similarly, Vatican Sayings was a foundational text on Epicurean friendship and was therefore used to meet goal (2). Since goal (3) represented a culmination of the themes of both egoism and friendship, all three sources were a part of the analysis of goal (3).

\section{Goal 1. Epicurean Pleasure and Rule Egoism}

As mentioned in the introduction, Epicurus maintained a paradigm of egoism. Scholars have previously interpreted his egoism as ethical egoism, but literary evidence found in both LL and DL suggests that a rule egoist reading of Epicureanism is plausible. For example, $\mathrm{LL} \mathrm{A}_{5}, \mathrm{~B}_{3}$ states, "the 'natural affinity' of every pleasure and the converse for

\footnotetext{
${ }^{33}$ Long and Sedley (1987), p.125

${ }^{34}$ Long and Sedley (1987), p. 21

${ }^{35}$ Inwood and Gerson (1988), p. 26

${ }^{36}$ For simplicity, this paper abbreviates Letter to Lucretius 6.1-28 as 'LL', Epicurus's Letter to Menoeceus: Diogenes Laertius 10.121-135 as 'DM', and The Vatican Collection of Epicuren Sayings as 'VS'
} 
every pain are not reasons for pursuing the former and avoiding the latter irrespective of circumstance. I.e. not every pleasure is choiceworthy." 37 Deconstructing this section of text provides valuable insight into Epicurus's egoism. Figure 1 below displays the same excerpt annotated to identify indicator words and themes. Bolded words and phrases represent sections of the text that were registered as an indicator word during the qualitative content analysis document coding. Words and phrases in blue represent literary evidence of rule egoism.

"the 'natural affinity' of every pleasure and the converse for every pain are not reasons

for pursuing the former and avoiding the latter irrespective of circumstance. I.e., not every

\section{pleasure is choiceworthy."}

Figure 1: Excerpt from Letter to Lucretius

As depicted, the indicator word of pleasure (which corresponded with category (1) in the coding process and goal (1) in the analysis) was present twice in the selected text. There are also three phrases present in the excerpt which indicate Epicurus's egoism as rule egoism rather than ethical egoism.

\section{Phrase 1 and Phrase 3}

The phrases 'are not reason' and 'choiceworthy' offer textually the same purpose and indicate that though every pleasure might entail a temporary satisfaction, this satisfaction is not consistent with a rational self interest, since our affinity toward pleasure is not a reason to pursue it. Specifically, Epicurus maintains that it is not reasonable to fulfill every pleasure. This is the first example of textual evidence that Epicurus's egoism is rule egoism rather than ethical egoism. Recall that ethical egoism maintains that we should always do what is in our self-interest. It is not concerned with differentiating which pleasures we should follow and which pleasures we should avoid. Rule egoism, on the other hand, is very much concerned with choosing only those pleasures which are rationally to pursue,

The aforementioned phrase entails that while Epicurus valued pleasure (or things that incited pleasure) as an ultimate goal, he did not propose a philosophy of pleasure Olympics. That is, Epicurus did not prescribe a life of only chasing pleasure but rather suggested that pleasure be pursued if it was rational under a larger, overarching goal. Therefore, Phrase 1 provides evidence of rule egoism in Epicurean philosophy.

\section{Phrase 2}

Epicurus is specific in mentioning that our pleasures should be chosen by us 'irrespective of circumstance'. In other words, our circumstance should not define which pleasures we decide to adopt to fulfill our self-interest. Hospers describe rule egoism in a very similar way, maintaining that rule egoism doesn't "talk about individual cases" of choosing pleasure. ${ }^{38}$ Ethical egoism, on the other hand, is dependent largely on circumstance. Under ethical egoism, it may be rational for me to steal a banana when no onlookers are present, but not when there is a crowd gathered by the banana stall; whether I pursue pleasure as an ethical egoist is determined largely by circumstance. As a rule egoist, however, I decide whether or not to adopt stealing as a general rule; my actions are not contingent upon circumstance. Accordingly, Phrase 2 provides strong evidence of a rule egoist reading of Epicureanism.

A second textual indicator of rule egoism is present in DL 129: "we do not choose every pleasure; but sometimes we pass up many pleasures when we get a larger amount of what is uncongenial from them." ${ }^{39}$ Epicurus here maintains that the pursuit of pleasure is only rational if it outweighs any accompanying pain. In other words, one should only

\footnotetext{
${ }^{37}$ Long and Sedley (1987), p. 21

${ }^{38}$ Hospers (1973), p. 394

${ }^{39}$ Long and Sedley (1987), p. 21
} 
pursue pain if the action of pursuing does not yield us more pain than it does pleasure. Reorienting DL 129 in terms of rule egoism presents us with a general rule (following pleasure) that must only be pursued when it is rational (when pleasure gained is greater than pain gained).

It is important to keep in mind that the excerpt analyzed above is not an isolated event of parallelism between Epicureanism and rule egoism. Numerous other incidents of textual evidence supporting a rule egoist-reading of Epicureanism (from the three included sources). The analysis of data shows, then, that goal (1) has been sufficiently met.

\section{Epicurean Friendship and Rule Egoism}

The next objective during data analysis was reconciling rule egoism with Epicurean friendship in accordance with goal (3). SV. 39 elaborates on the nature of Epicurean friendship: "The constant friend is neither he who always searches for utility, nor he who never links [friendship to utility]. For the former makes gratitude a matter for commercial transaction, while the latter kills off good hope for the future." ${ }^{40}$ Here, Epicurus maintains that there are conditions (rules) for maintaining a virtuous friendship that dictate the productivity of that friendship. A friend who is too needy is not a productive one to have; the friendship becomes commercial and material to one actor while worthless to the other. A friendship based on material gain is also unsatisfactory; such friendships usually do not last through hardships and time. Epicurus holds that a symbiotic friendship (a rational friendship) occurs only as a result of both parties submitting to certain rules about how the friendship governs. In other words, a rule-based interpretation of Epicurean friendship draws undeniable parallels between rule egoism and friendship, fulfilling goal (2).

\section{Reconciling Friendship with Epicureanism}

Section (1) and (2) of data analysis have established that Epicurean philosophy and, more specifically, Epicurean friendship are compatible with a notion of rule egoism. This section (in accordance with goal (3)) aims to establish that a rule-egoist notion of Epicurean pleasure is compatible with Epicurean friendship. As discussed prior, the problem compatibilists face in reconciling friendship and egoism is that an Epicurean friendship must both arise from utility toward both parties and exist for its own sake. Accordingly, a friendship must be both choiceworthy for itself but have an initial cause in some advantage.

Re-examining a rule-egoist philosophy of egoism is helpful. Recall that (consistent with rule-egoism) Epicurus maintains that the pursuit of pleasure is good so long as our pursuit is not dependent on circumstance, and is founded in reason. If we take friendship to be a pleasurable activity (consistent with Epicurus's views), then the statement reads: the pursuit of friendship is good, as long as we do not gain more pain from the friendship than pleasure, and the friendship is a rational one. I also established in section (2) that under rule egoism, a friendship is valuable as long as it is reciprocal (as long as one party does not materially benefit at the expense of the other). Thus, the same rule can be applied in this case: a friendship can be valuable for itself as long as the continuation of the friendship provides some benefit or utility to its participants.

Consider, for example, a friendship between an Epicurean scholar and a historian. It is possible for such a friendship to arise out of some utility (perhaps a joint collaboration on a research paper) and exist for its own sake (both enjoying each other's company and conversation). The same situation can be generalized toward all Epicurean friendships. It can be maintained as a rule that while all Epicurean friendships can arise from some utility, they must be maintained for their own sake. Thus, goal (3) of reconciling hedonism and friendship is also fulfilled.

${ }^{40}$ Inwood and Gerson (1988), p. 26 


\section{Conclusion}

Epicurus undoubtedly maintains a position of egoism through his scholarship. While some Epicurean scholars interpret this egoism as ethical egoism, there is generous evidence to indicate that a rule-egoist reading of Epicurus is also plausible. Under the paradigm of rule egoism, inconsistencies within Epicurean philosophy can be resolved. In the context of rule egoism, Epicurean friendship is seen as a general rule which provides pleasure consistent with rational self-interest. Since such a reading of friendship is compatible with rule egoism, Epicurean friendship is able to remain internally consistent with Epicurus's egoism.

\section{Implications}

The scope of this research project includes the implications of applying rule egoism both as a general concept and to other facets of Epicureanism. As previously mentioned, much of the literature surrounding interpretations of Epicurus include an ethical-egoist reading. This paper provides a foundation for broadening the extent of the egoism behind Epicurus's paradigm.

\section{Rule Egoism as an Ethical Theory}

Rule egoism, while powerful in its implications, remains an undeveloped ethical theory in modern philosophy. The most significant contribution to establishing rule egoism as a formal philosophical postulate comes from John Hospers' Rule-Egoism. Although Hospers provides a function definition of rule egoism and contrasts it with other forms of egoism (such as ethical egoism), prior to this paper, rule egoism has yet to be applied to existing paradigms and epistemologies. Therefore, this paper serves as a foundation for interpreting other philosophical texts under rule egoism.

\section{Rule Egoism in Epicureanism}

As previously mentioned, the extent of Epicurus's philosophy is wide ranging; he covers scientific, religious, ethical and moral principles in numerous treatises. As is expected with any expansive philosophy, problems arise when reconciling different aspects of Epicurus's school of thought. While the intent of this paper was to resolve Epicurean friendship and egoism, it also provides an underpinning to applying rule egoism to other facets of Epicureanism. The textual evidence cited in the Data Analysis section is not unique to friendship alone; there is significant indication from passages in Diogenes Laertius and SV 23 that allow Epicurean ethics (in general) to remain compatible with rule egoism. AN interpretation of Epicureanism not only advances the field of Epicurean study from the previously recognized ethical egoism, but it also serves as a possibility of resolving future conflicts that may arise from Epicurus's teachings.

\section{Limitations}

Due to the subjective nature of philosophical research, there exist two limitations to the parameters of this research project.

\section{Application of Rule Egoism}

First, the evidence reviewed to establish a rule-egoist reading of Epicurus were texts primarily focused on resolving Epicurean ethics. Therefore, while rule egoism can be applied to ethical issues, there exist problems when trying to apply rule egoism to other facets of Epicureanism such as his physics.

Although such a limitation exists, it is not detrimental for two reasons. First, the problems that exist within Epicureanism are condensed mainly to his ethics and philosophy. Treatises regarding physics and science, while 
ground-breaking, are widely regarded as scientifically inaccurate (with respect to modern standards). Because of this, problems in Epicurus's science are not a critical obstacle to either the scientific or philosophical fields. Thus, questions like "can rule egoism be applied to Epicurus's science" are irrelevant in the larger scope of Epicurean scholarship.

Second, I argue that, if necessary, sufficient evidence can be collected to interpret Epicurus's science under a paradigm of rule egoism. In other words, since consistency among Epicurus's ethics and science is (generally) maintained, such a consistency is likely to manifest itself in rule-egoist readings of Epicurean science and physics.

\section{References}

Annas, Julia. 1989. “Epicurean Emotions,” Greek, Roman, and Byzantine Studies 30(2): 145-64.

Annas, Julia. 1993. The Morality of Happiness. New York. Oxford University Press.

Bales, R. Eugene. 1971. “Act-utilitarianism: Account of Right-making Characteristics or Decision-making Procedure?” American Philosophical Quarterly 8: 257-265.

Baird, William. 2011. "Friends with Benefits: Other Regarding in Epicurean Ethics" Georgia State University

Bardach-Yalow, E. (2012) “Analyzing Russian Propaganda: Application of Siegfried Kracucer' qualitative content analysis method" Journal of Information Warfare, Vol. 11, No. 2, pp . 24-36

Evans, Matthew. "Epicurus on the Security of Friendship," unpublished manuscript.

Hare, R. M. 1981. Moral Thinking: Its Levels, Method, and Point. Oxford. Oxford University Press.

Hospers, John. 1973. "Rule-Egoism” The Personalist

Inwood, Brad, and Gerson, L.P. 1988. Hellenistic Philosophy: Introductory Readings Indianapolis. Hackett Publishing.

Long, A.A., and Sedley, D.N. 1987. The Hellenistic Philosophers. Volume 1: Translations of the Principle Sources, with Philosophical Commentary. Cambridge. Cambridge University Press.

Margheim, Stephen. (2013). "What Epicurean Friendship is Not: The Vulgar and the Divine" unpublished manuscript.

Mitsis, Phillip. 1988. Epicurus’ Ethical Theory: The Pleasures of Invulnerability. Ithaca. Cornell University Press.

O’Connor, David. 1989. “The Invulnerable Pleasures of Epicurean Friendship.” Greek, Roman and Byzantine Studies 30: 165-89.

O’Keefe, Tim. 2001. "Is Epicurean Friendship Altruistic?” Apeiron, vol. 34 no. 4, 269-305 
Purinton, Jeffrey. 1993. "Epicurus on the telos," Phronesis 38(3): 281-320

Rackham, H., trans. 1931. Cicero, De Finibus Bonorum et Malorum. Cambridge. Harvard University Press.

Regis, Edward Jr. (19680) “What is Ethical Egoism?” Ethics, Vol. 91, No. 1, pp. 50-62

Riska, Agustin. (1972) "Methodology and Philosophy” Vol. 3, No. 3 (July 1972), pp. 219-237

Rist. John. 1972. Epicurus: An Introduction. Cambridge. Cambridge University Press.

Usener, H. 1887. Epicurea. Leipzig. Irvington Pub. 